\title{
Effect of Liberating Approach of Teaching on Students' writing skills in English at Secondary School
}

\author{
a Munwar Bagum, ${ }^{\text {b }}$ Abid Hussain Chaudhary \\ a Ph.D Scholar, Institute of Education and Research, University of the Punjab, Lahore, Pakistan: munwarzara555@yahoo.com \\ b Professor of Education, Institute of Education and Research, University of the Punjab, Lahore: abid.ier@pu.edu.pk
}

Corresponding author’s email address: munwarzara555@yahoo.com

\begin{tabular}{l}
\hline ARTICLE DETAILS \\
\hline History: \\
Accepted 15 April 2019 \\
Available online 30 June 2019
\end{tabular}

Keywords:

Liberating, Approach, Teaching, Writing, Secondary School

\section{JEL Classification:}

B10, A20, I21

DOI: $10.47067 /$ real.v2i1.10

\section{ABSTRACT}

Current The major purpose of this study was to compare the effectiveness of liberating approach of teaching with banking approach of teaching in the subject of English at secondary level in Pakistan. In order to develop the rational of the study, an experiment was devised to identify the effect of liberating approach of teaching on students' achievement in the subject of English at secondary school level. Through this approach student creativity and mental power is stimulated and better used in academic and social context. The population of the study was included all the students of science and arts enrolled in gth class in girls' comprehensive higher secondary school of the Multan city. The researcher was selected two intact group sections of English medium science and both the sections have total 104 students. The study was Quasi Experimental with a Non-equivalent control group pre-test posttest design. One section was randomly selected an experimental group (X1) and the other was assigned to control group (X2).A pre-test and post-test were developed by the researcher, through carefully reviewing the methods of test development regarding quantifying students language skill, that is writing skills. A panel assessed the validity of both the test. The test had 50 marks for writing capacity (writing skills test).A pilot study was conducted to validate the instruments.The results also showed that treatment enhanced the achievement level of the experimental group in English. The researcher has confirmed that liberating approach is connected with learning techniques and strategies; and it is recommended that teacher of English should apply liberating approach to improve writing skills of the students in the classes. The findings revealed that liberating approach is more effective as compared to banking approach (traditional) of teaching. It is recommended that the teachers should apply liberating approach of teaching in the classes in order to improve writing skills of the students.

(C) 2019 The authors. Published by SPCRD Global Publishing. This is an open access article under the Creative Commons Attribution- 


\section{Introduction}

The impact Teaching English language in Pakistan is an essential part of the educational curricula at the secondary school level. English language is mostly taught through teacher centred approach in educational institution in Pakistan, especially in public schools. This approach neither results in effective teaching of English language to the learners nor does it develop critical thinking among the learners at secondary school level. It means that the learners have been feeding with information and knowledge in large quantity and are expected to reproduce the same information in the examination without thinking Freire (1972) suggested that the learners who are taught through the teacher centred approach mostly become banks where the teacher keeps on storing the information provided by him and expects from student to reproduce the same in examination. Freire, therefore, names traditional approach of teaching as "Banking Approach". He uses the term 'banking' to describe the teaching situation where the teacher delivers lectures and students listen, memorize, and reproduce information.

According to Freire (2000) banking approach depends largely on the following points:

1. The teacher speaks and students listen modestly.

2. The teacher teaches and students are taught.

3. The teacher is well familiar with everything and students are ignorant.

4. The teacher disciplines and students are disciplined.

5. The teacher ponders and students are thought about.

6. The teacher selects and implements his choice whereas the students comply.

7. In the learning process, the teacher is the subject whereas students are just objects.

8. The teacher acts and students have the delusion of acting as per action of the teachers.

9. With his or her professional authority, the teacher uses authority of knowledge which is in opposition to the freedom of the learners.

10. The teacher selects the content of the program while students (who were not involved in consultation) adjust to it.

The above mentioned discussion reveals that the banking approach is used while keeping in mind that human beings are manageable and adaptable. The more the students make efforts in storing the deposits assigned to them, less they establish the critical thinking approach which comes as consequence form their intervention in the world as being transformers of that world. The more they allow the passive role to live in, the more they incline to adjust to the world the way it is and also to the disrupted view of reality grounded on them.

On the other hand, liberating approach for teaching young learners is the utmost necessity of modern day education. Brown (2013) describes that problem-posing pedagogy is the process of teachers and students working together to solve community issues. Teachers use this process to teach necessary knowledge and skills integrated in an effort to debate and solve the community issue. Francis (2001) has suggested following significant principles of liberating approach of teaching:

- $\quad$ Liberating approach demands that teacher must learn from the student and student from the teacher, resulting in a strong educational bond between the two.

- Problem posing education is another main pillar of liberating approach to learning. Here the learner must be prepared to face the situation and he must make utmost effort to resolve the issue. 
- $\quad$ The liberating approach of teaching must uplift and liberate the mind of the learner by allowing him to go through question and answers.

This research aims to explore the possibilities of the effectiveness of teaching English through liberating approach in our schools and determine up to what extent liberating approach of teaching is more useful in teaching English as compared to the traditional teacher centred approach. Therefore, the researcher will conduct experiment in order to evaluate the effectiveness of the use of liberating approach of teaching.

The experts of education have already worked on it and have proposed teacher-centred and student-centred approach of teaching and have found the student-centred approach to be more effective in learning. This review of the literature is meant to find out the gaps in the teacher-centred approach to further make it effective for the teaching of English at school level. The theoretical frame work is drawn from the Frere's Ideology of liberating education who has proposed an approach of teaching in his book "Pedagogy of the oppressed".

The traditional approach of teaching English has not been so far able to produce desired results of teaching English. This means, at least, four skills of English, speaking, reading, writing and listening are fully developed. It is, therefore, necessary that a new approach of teaching English may be developed and implemented. The new approach, according to Freire (2000) should focus on critical thinking and practical approach. This is termed as liberating approach of teaching or problem posing teaching methodology. In educational process, the method of teaching has gained much importance because it is the way to achieve teaching objectives.

Robert (2006) also observed the same thing and claims that Freire.s emphasis lays on this method. Further, he makes clear that his emphasis is particularly on direction, structure and rigor in liberating education. Thus, his pedagogy can best be understood not just as a method but as a different approach towards theory and practice of education. He calls it liberating approach and asserted that it is opposite to the shift of many western countries towards technocratic and "market-driven" systems of education and assessment.

Critical thinking underpinned the liberating approach of teaching as findings of Mayo (2007) revealed that the liberating approach produces the learners who develop natural power of thinking that can liberate them from traditional enslaving of education and learners.

Leonard and Mclaren (2002) highlighted that it was assumed by banking model of schooling that knowledge may be transferred from the teacher to the student as student can absorb the knowledge, unchanged. The teacher possesses the authority, the teacher is the font of knowledge and student is an empty vessel, which comes to the teacher, to be filled with knowledge.

This section discusses the notion of Frerian dialogic pedagogy by making clear that how it is liberating relating the grounding programme under study. It also brings under study. It also brings under discussion features of dialogue, kinds of questions associated with dialogue, kinds of questions associated with dialogue and how the flow of dialogue is ensured by the facilitators through uptake. It also emphasizes the monologic nature that discourages dialogue.

The education system needs to help students in developing their identity, at the end of the day and free the students from being shaped by family, friends and society. Regarding the liberating aspect of the 
students, the teachers become an influential tool. According to Freire,

"The teacher is of course an artist, but being an artist does not mean that he or she can be make the profile, can shape the students. What the educator does in teaching is to make it possible for the students to become themselves" (Freire and Horton, 1990).

Hence, it signifies that teacher neither impose neither his / her ideas nor the ideas that teacher has obtained from the textbooks, and get it deposited into their minds. Most of the, who got educated in the traditional 'banking system', must accepted the shift to dialogism, initially by admitting this, that an input to learning can also be made by the students by including in this the teacher learning from the students. Further, Freier argues that:

"One cannot expect positive results from an educational or political action program which fails to respect the particular view of the world held by the people. Such a program constitutes cultural invasion, good intentions not withstanding" (Freire, 1972).

Therefore, it is a call to be acknowledged, to the educational system, that in order to get success in the education system the students' ideas are of great significance. In the education system, students should take responsibilities regarding the change of their situation. Students must liberate themselves from the oppression of those who hold the position of more knowledgeable ones and made obligatory for students to receive knowledge from them. Freire (1972) contends that, "The greatest historical and humanistic task of the oppressed: to liberate themselves". It is the responsibility of the students to highlight the need that is required to liberate them from the system that is creating problems and also cripples students to work creatively in rest of their lives. That kind of educational system delimit their (students) potential by curtailing them in doing and not doing task in the classroom.

Skidmore (2000) cites Lyle, who argues that "an emancipator alternative is offered by a dialogical concept of learning and teaching regarding the traditional power relationships of classroom which is inclined to produce a pedagogy based on the transmission of pre-packaged knowledge".

Dialogism liberates the students as the rules of authoritative learning and teaching cannot bound the students. Action and language can give any one the potential to "change social context," "engage in dialogue" and "develop new knowledge" (Gomez et al., 2010).Dialogue engagement makes people 'transformative agents', their knowledge change lives and contexts; huge changes come as people have given the opportunity to become social agents (Pardros et al, 2011).

Freire (1972) mentioned that in 'banking education'; education is trapped that makes student an empty container, which teacher has the responsibility of filling with information. The rules placed in the class, strengthened the position of the teacher and it states that:"the teacher selects or decides and enforces it, and it, and the students have the illusion of acting through the action of the teacher", "the authority of knowledge gets confused with teacher sets in opposition to the freedom of the students"(Freire,1972,p:73). Being influenced by the oppressive society where he had lived, he viewed education as a true reflection of the oppressed and oppressors' society. In this regard, teacher had the role of oppressor whereas student was oppressed.

Freire (1972) mentioned that knowledge making was thwarted in banking education as constructing and reconstructing of ideas between people involved in a dialogue is a source of knowledge. 
Regarding liberation in education, Freire (ibid) believed that the standard roles of teacher and student (oppressor/oppressed) first, had to be broken. Freire (ibid) mentioned that, to the education system, dialogue is a concept in which student and teacher both played the role of contributors to knowledge.

Rogoff (1991, p.191) discusses the "notion of guided participation" and it provides an "alternative discourse framework in which children's interactions with others, including just not exclusively the teacher" by the way of providing help regarding the comprehension and development by the learners. Related to this, Mercer (2002) also agreed that guidance has been provided to learners by the teachers regarding critical thinking.

Alexander (2004) advocated dialogue instruction as this interaction is genuinely 'cumulative and reciprocal' because it is opposed to the classroom discourse (question and answer) and it is also termed as "interactive teaching". Skidmore (2000) also indicated that genuine reciprocal dialogue in classrooms has more significance as it develop the reflective capacity of learners. This room for reflection by dialogue also liberates the learners in classroom.

As discussed above, the teaching approach is very significant in the teaching process and that teaching approach (Liberating approach) proves more helpful in making the learners more active learners. In present study, the researcher will intend to explore the missing links in the teaching process within the perimeters of Student centred approach and will discuss improvement level of learning among the students with an idea of making them effective learners, and good citizens.

There is an increasing trend of learning English language throughout the world. English language learners and schools are always at guards to confirm that educational practices and facilities to teach English language are sufficient and that students, are attaining the expected success and achieving predetermined goals at the end of every academic year. Educational environment, students, strength, classroom size, community and society all greatly affect while choosing an appropriate, 'one size fits all 'approach of English language learning (Anjum, 2017).

The study will aim to determine the effect of liberating approach in comparison to banking approach at secondary school level. It is due to the use of banking approach of teaching and ignoring the modern critical pedagogies in academic setting. The learners are mostly trained with the view of scoring higher marks by making them memorise information and knowledge without any understanding and then making them reproduce the same in the examination. This process does not liberate their minds and hence they become a type of banks of information. The learners may succeed in gaining higher scores, especially at the school level and generally at college level by using this concept but at the professional level such students do not flourish (Brown, 2013). This laid emphasis on liberating approach of teaching at schools which depends largely on the involvement of the students' in the teaching process.

The present study will measure the effect of Liberating Approach of teaching on students' achievement (writing skills) in the subject of English at Secondary school level.

Liberating approach of teaching will be more useful for the writing skills in the students. However, this research will be delimited to the development of writing skills because the existing examination system particularly focuses evaluation of this skill. This research will be helpful in developing an effective English language teaching approach at secondary school level, through liberating approach of teaching that would be helpful to overcome all the drawbacks of the existing traditional teaching methods. Further 
liberating approach of teaching will be helpful in removing the class room boredom for the students which may increase the efficiency of learning in the class room.

This study will help the teachers, heads of the institutions, administrators and authorities in adopting new teaching strategies and methods to overcome difficulties in teaching English language. This research will further help the policy makers to design curriculum accordingly. It will make learning of writing skills of English language easier for the students. This research may also prove to be useful for the future researchers in the field of teaching pedagogies.

Therefore, this research will be useful for teachers to engage the students to actively participate in classrooms. The teachers will work through dialogues and active participation that will help the learners to liberate their minds. This research study will provide an opportunity to develop liberated, tolerant and critical thinking environment in educational institutions.

\section{The objectives of the study were to be:}

- Find out the effect of liberating approach of teaching on students' achievement in the subject of English at secondary school level.

- Compare the effectiveness of liberating and banking approach of teaching on students' achievement in the subject of English at secondary school level.

\section{Research Hypotheses}

The Hypotheses were tested in this study:

Ho1: The pre-test mean scores has no statistically significant mean difference on creative writing skills of gth grade students in the English subject who had been taught through banking approach of teaching.

Ho2: The post-test means scores have statistically significant mean difference on creative writing skills of 9th grade students in the English subject who had been taught through banking and liberating approach of teaching.

Ho3: The pre-test and post-test mean scores have no statistically significant difference on creative writing skills of 9th grade students in the English subject who had been taught through banking approach of teaching.

Ho4: The pre-test and post-test mean scores have statistically significant mean difference on creative writing skills of 9 th grade students in the English subject who had been taught through liberating approach of teaching.

\section{Methodology}

It was experimental study. The main aim of the research was to study the effect of liberating approach of teaching in English subject. In this research, pre-test, post-test, quasi-experimental (nonequivalent groups) and control group design was used. The treatments to the intact groups were randomly assigned.

\subsection{Population of the Study}

Population of the study was included all the students of science and arts enrolled in 9th class in girls' comprehensive higher secondary school of the Multan city. There were seven sections of 
9thclass.Two sections were for English medium science, two for Urdu medium science and three for Arts. The total numbers of students enrolled in the class are 386.

\subsection{Sample and Sampling Procedure}

The experiment was conducted at government girls' comprehensive highest secondary school Multan. In the above mention school the ninth class has seven sections and these sections have total 386 students. The average of each section is 55 students per section. Two sections were for English medium science, two for Urdu medium science and three for arts. The researcher was selected two intact group sections of English medium science and both the sections have total 104 students. The age level of research participants ranges from 14-15 years. All the research participants (students of ninth class) were homogenous concerning first language, gender, age, authenticity, exposure to English language, culture and educational back ground.

The research study was quasi experimental while including pre-test, post test and nonequivalent control group design. Randomly one section was assigned to experimental group(x1). Whereas, the second section was assigned to control group (X2). Further, different variable in the circumstances were controlled to a maximum extend.

\subsection{Intervention}

The conditions for both groups were equally maintained. The experimental group was taught by the researcher and control group was taught by the teacher. In order to employ the liberating approach of teaching in the treatment of experimental group, the researcher played an important role of a model, mentor, helper, evaluator, facilitator and a social worker for the students. The traditional approach (Banking approach) of teaching method was used for giving instructions to the control group. The total duration of study was four months, with 35 minutes daily.

\subsection{Instrumentation}

The comparison of experimental and control groups were on the grounds of their previous class outcomes and a teacher prepared a pre-test. Soon after the treatment was given post-test was prepared by teacher and it was also administered to subjects of control and experimental groups. The pre-test and post-test were developed by the researcher, through carefully reviewing the methods of test development regarding quantifying students 'two language skills, that are, reading skills and writing skills. Pre-test and post-test were equally same. Thus, organizations of items were different in both tests. The panel assessed the validity of both the test. The panel included specialists in the field of English, training subject and instructors. The test 50 marks for writing capacity (writing skills test). The writing test validity is evaluated through content, subject specialists (English subject) and concerned teachers of the schools.

\subsection{The Writing Test}

The writing test comprised of different topics. The writing test activity includes five items. The students wrote paragraphs, essay and summary on the provided topic. Dialogue writing was also done by the students. The students did creative writing on the given topics.

\section{Data Analysis and Findings}

Table 1: Independent sample t-test of pre- test means scores.

\begin{tabular}{|c|c|c|c|c|c|c|c|}
\hline Variable & $N$ & $\mathbf{M}$ & SD. & MD & f. $\quad$ d & value $^{t-}$ & ig. \\
\hline $\begin{array}{l}\text { Control } \\
\text { group }\end{array}$ & 5 & 15.8 & $418 \quad 4.52$ & $\begin{array}{ll} & .63 \\
485 & \end{array}$ & 02 & 610 & 43 \\
\hline
\end{tabular}




\begin{tabular}{|c|c|c|c|}
\hline $\begin{array}{l}\text { Experim } \\
\text { ental group }\end{array}$ & $3 \quad 5$ & $887^{15.1}$ & $\begin{array}{ll} & 5.95 \\
514 & \end{array}$ \\
\hline
\end{tabular}

The findings in Table 1 makes clear that mean values for control group $(M=15.8235, S D=4.52418)$ are relatively same as experimental group. Moreover the results of independent sample t test, in context of scores comparison of mean pre-test of control and experimental groups concerning writing comprehension are also presented in Table 1. Therefore, through the above findings in table 4.6 , it can be inferred that there is no significant difference and both the groups performed equally before conducting the experiment. So, based on above findings the null hypothesis that "there is no significant mean difference between the pre-test scores in English; writing comprehension of both groups of 9th grade students, who group have been taught through liberating approach and second group who have been taught though banking approach of teaching ".

Table 2 : Independent sample t-test of post-test mean scores.

\begin{tabular}{|c|c|c|c|c|c|c|c|}
\hline Variable & $N$ & M & SD. & MD & f. & value $^{\mathrm{t}-}$ & ig. \\
\hline $\begin{array}{l}\text { Control } \\
\text { group }\end{array}$ & 5 & 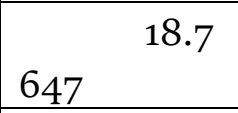 & $\begin{array}{ll} & 7.61 \\
469 & \\
\end{array}$ & $\begin{array}{ll} & 13 \cdot 4 \\
6171 & \\
\end{array}$ & $\begin{array}{ll} & 1 \\
02 & \\
\end{array}$ & $\begin{array}{l} \\
057 \quad 9 . \\
\end{array}$ & 000 \\
\hline $\begin{array}{l}\text { Experim } \\
\text { ental group }\end{array}$ & 5 & 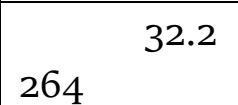 & $7 \cdot 54$ & & & & \\
\hline
\end{tabular}

The readings in Table 2 exhibits that mean values for control group $(M=18.7647, S D=7.61469)$ lower than the experimental group. Further, the findings of independent sample t test, in context of scores comparison of mean post-test of control and experimental groups regarding writing comprehension are also given in table 2. Hence, through the above findings in table 4.7 , it can be inferred that there is significant difference between the performance of two groups. Thus according to above findings the research hypothesis that "there is significant mean difference between the post-test scores in English subject; writing comprehension of both groups of gth grade students, first group who have been taught through liberating approach and second group, who have been taught by banking approach of teaching, "is accepted.

Table 3: Paired sample t-test difference of pre-test and post-test mean scores.

\begin{tabular}{|c|c|c|c|c|c|c|c|}
\hline Tests & $\mathbf{N}$ & $\mathbf{M}$ & SD. & MD & f. $\quad$ d & value $^{\mathrm{t}-}$ & g. \\
\hline $\begin{array}{l}\text { Pre- } \\
\text { test }\end{array}$ & 5 & $\begin{array}{ll} & 15.8 \\
235 & \\
\end{array}$ & $4 \cdot 52$ & 118 & 5 & 2.6 & 11 \\
\hline $\begin{array}{ll} & \text { Postt } \\
\text { est } & \\
\end{array}$ & 5 & $\begin{array}{ll} & 18.7 \\
647 & \\
\end{array}$ & 7.614 & & & & \\
\hline
\end{tabular}

The results of paired sample t-test in order to identify the mean values of pre-test and post-test scores of group are given in table 3 . In pre-test $(M=15.8235, S D=4.52418)$ the mean scores of control group are relatively less than mean scores of post-test $(M=18.7647, S D=7.61469$. Moreover, the findings of paired sample t test done, in comparison mean score of pretest and posttest of control group for writing comprehension, is presented in table 3. Thus, it can be inferred that "there is no significant difference between the performance of pre and posttest. Considering the above mention findings of table 4.8 , the research hypothesis that there is no significant mean difference between the pre and post test scores of 
English subject, writing comprehension of control group of gth grade students who have been taught through banking approach of teaching", is rejected. Hence it is concluded that students in the control group performed equally before and after the treatment.

Table 4; Paired sample t-test mean of pre-test and post-test scores.

\begin{tabular}{|c|c|c|c|c|c|c|c|}
\hline Test & $\mathbf{N}$ & $\mathbf{M}$ & SD. & MD & f. & value ${ }^{t-}$ & g. \\
\hline $\begin{array}{ll} & \text { Pret } \\
\text { est } & \end{array}$ & 5 & 15.18 & 5.95 & $\begin{array}{ll} & 17.03 \\
774 \\
\end{array}$ & 2 & $968 \quad 17$. & OO \\
\hline $\begin{array}{ll} & \text { Postt } \\
\text { est } & \end{array}$ & 3 & $264 \quad 32.2$ & $7 \cdot 54$ & & & & \\
\hline
\end{tabular}

The results of paired sample t-test in order to identify the mean values of pre-test and post-test scores of experimental group are given in table 4 . In pre-test $(M=15.1887, S D=5.95514)$ the mean scores of experimental group are relatively less than mean scores of post-test $(M=32.2264, S D=7 \cdot 54127)$. Moreover, the findings of paired sample t test done, in comparison mean score of pretest and posttest of experimental group for writing comprehension, and is presented in table 4.Thus, it can be inferred that "there is significant difference between the performance of pre and posttest. Considering the above mention findings of table 4.9, the research hypothesis that there is significant mean difference between the pre and post test scores of English subject, writing comprehension of experimental group of gth grade students who have been taught through liberating approach of teaching”, is accepted. Hence it is concluded that students in the experimental group performed better after the treatment.

\section{Conclusion}

On the basis of findings, it is concluded that the students of gth grade in Government Girls Comprehensive higher secondary school, Multan have a good and higher level of performance with liberating approach of teaching as compared to the banking approach. The conclusion is based on the pretest and post-test. The instructions and directions in banking approach is one of the important reasons for students' poor performance in the subject of English.

The results proposed that the students concentrated their thinking; they have an ability to solve the problem and dialogical participation between the teacher and students. When students were frightened to express their ideas in the class, it resulted in taking stress and lack of creativity. In this context, the liberating approach reduced their anxiety. The participants in the experimental group perform best with less stress. When the students read English lessons and solve exercises, they took active participation in the classroom and they wrote summary and paragraph in their own words. In this way writing of English language developed like leisure by pursuit.

\section{Discussion}

The findings revealed that there was a significant difference between the mean scores of the control and experimental groups regarding reading comprehension and creative writing activities that had been taught through liberating approach instead of banking approach of teaching. In the experimental group, on students reading comprehension and creative writing abilities, the liberating approach of teaching had a strong influence as compared to the banking approach.

Concerning liberating approach of teaching in English subject there was significant difference between the post-test scores of students, who had been taught through liberating and banking approach 
of teaching. The results clearly showed that the students of experimental group performed well as compared to the students of control group. Therefore, it advocates that liberating approach of teaching guides the students to work and study comfortably in the classroom without having much pressure from the teachers. In liberating approach of teaching, students can share their knowledge, feelings and ideas in class with teachers and class fellows. Students felt relaxed in reading the English text and their confidence level increases while communicating in English with their group members during class discussion.

The results showed that in creative writing in the subject of English there was a significant difference in the post-test scores of the students who had been taught through liberating approach (experimental group) as compared to the students who had been taught through banking approach (control group) of teaching. The result stands consistent with findings of Akabr and Fatima (2018), who stated that the students of a secondary school possess poor writing skills. In this context, examination system can be the primary reason as it is the basic cause of demotivating students. The aim of examination system was just to get highest marks. It assesses only memorization instead of practical application of the knowledge.

The findings are consistent with the results of Barton et,al.,(2010) which highlighted that learning and teaching in a dialectical relationship among teachers and students is part of liberating and critical pedagogical practices and in this students because active participant in class and outside the classroom. These practices help students in enhancing their skills and abilities to ask questions, and explore subjects that eventually lead to acquiring knowledge. As knowledge is the main gate way to improvement.

\section{Recommendations}

Considering the findings of the study, following recommendations have been made:

The findings revealed that liberating approach is more effective as compared to banking approach (traditional) of teaching. It is recommended that the teachers should apply liberating approach of teaching in the classes in order to improve reading comprehension of the students. The Intermediate result Multan Board declared that the students' performance in English subject is very poor. The findings of the study also showed that for the banking approach of teaching training is required. Therefore, it is recommended that workshops and different teachers training programs should be arranged to guide teachers about the use of liberating approach of teaching. It is recommended that in order to effectively improve the performance of students, liberating approach must be integrated with the instructional practices. In this context English language centers need to be maintained for the development of students' skills. It also suggested that teacher should employ liberating approach in the classroom by engaging students in the learning process, like enhancing their critical thinking, giving them problem solving tasks, encouraging them to ask questions in the class and by helping them in maintaining creativity. It is recommended that the school administrator must ensure that teachers are implementing liberating approach in evaluation of the students. As through this, self-direction and confidence level of the students will be improved and resultantly, it helps them in improving reading and writing abilities. Related to it, future researches must be conducted in other subjects besides English and research should be extended on different levels like primary, secondary, college and university in order to find the usefulness of liberating approach.

\section{References}

Alexander, R. (2004). Dialogic teaching and the study of classroom talk. In International Conference 
keynote address (Vol. 44, No. 3, pp. 103-111).

Anjum,F. (2017).Developing effective English language teaching model at elementary school level (M.Phil. Thesis).Institute of Social Sciences, Bahauddin Zakariya University Multan.

Barton, A., Corteen, K., Davies, J., \& Hobson, A. (2010). Reading the word and reading the world: The impact of a critical pedagogical approach to the teaching of criminology in higher education. Journal of Criminal Justice Education, 21(1), 24-41.

Brown, P. M. (2013). An examination of Freire's notion of problem-posing pedagogy: the experiences of three middle school teachers implementing theory into practice (Doctoral dissertation, University of Georgia).

Fatima, Q., \& Akbar, R. A. (2017). Comparison of teaching practices in English writing classrooms of secondary school certificate and general certificate of education ordinary level. Journal of Educational Research, 20(2), 15-27.

Francis, T. (2001). Pedagogy of the Oppressor: Freirean Pedagogies in the Postmodern Classroom (Doctoral dissertation, Florida Atlantic University).

Freire, P. (1972). Pedagogy of the Oppressed. 1968. Trans. Myra Bergman Ramos. New York: Herder.

Freire, P. (2000). Pedagogy of the oppressed (30th anniv. ed.). New York: Continuum, 35.

Gómez, A., Racionero, S., \& Sordé, T. (2010). Ten years of critical communicative methodology. International Review of Qualitative Research, 3(1), 17-43.

Horton, M., \& Freire, P. (1990). We make the road by walking: Conversations on education and social change. Temple University Press.

Leonard, P., \& McLaren, P. (Eds.). (2002). Paulo Freire: A critical encounter. Routledge.

Mercer, N. (2002). Words and minds: How we use language to think together. Routledge.

Robert,P.(2006). Structure, direction and rigour in liberating education. Retrieved fromhttps://doi.org/10.1080/0305498960220304

Rogoff, B. (1991). Social interaction as apprenticeship in thinking: Guided participation in spatial planning. American Psychological Association.

Skidmore, D. (2000). From pedagogical dialogue to dialogical pedagogy. Language and Education, 14(4), 283-296. 